\title{
Meme Kanserli Kadınlarda Tamoksifen veya Tamoksifen+Leuprolid Asetat Tedavisi Alanlarda Endometrial Patoloji Sonuçlarının Karşılaştırılması
}

\author{
Vedat UĞUREL ${ }^{1}$, Mehmet Musa ASLAN ${ }^{2}$
}

\begin{abstract}
$\ddot{\mathbf{O z}}$
Meme kanserli olgularda tamoksifen kullanımına GnRH agonisti eklenmesinin endometrial patoloji ve endometrial kanser oranlarına etkisinin araştırılması planlandı. Retrospektif yapılan çalışma 1998 ile 2013 yılları arasında meme kanseri nedeniyle opere olan ve Trakya Üniversitesi Tıp Fakültesi Hastanesi jinekoloji polikliniğinde endometriyal örnekleme yapılan 204 olgu, sadece tamoksifen alanlar ve tamoksifen+GnRH agonisti(leuprolide acetate depot $11,25 \mathrm{mg}$ ) tedavisi alanlar olarak iki gruba ayrıld. Tamoksifen ile birlikte $\mathrm{GnRH}$ agonisti kullanan premenopozal kadınlar ile tamoksifen kullanan postmenopozal kadınlar arasında ultrason incelemesinde endometrial kalınlık, histopatolojik incelemede endometrial patoloji bulunma ve endometrial kanser görülme oranları açısından gruplar arasında fark bulunmadı. Meme kanserli hastalarda tamoksifen tedavisine GnRH anoloğunun eklenmesi premenopozal kadınlarda premalign lezyon ve endometrium ca riskini arttırmadığını saptadık.
\end{abstract}

Anahtar Kelimeler: Meme kanseri, tamoksifen, GnRH analoğu, leuprolid asetat, endometrial patoloji, endometrial kanser
Yayın Bilgisi

Gönderi Tarihi:14.09.2018

Kabul Tarihi:13.11.2018

Online Yayın Tarihi:30.06.2019

DOI: $10.26453 /$ otjhs. 460155

Sorumlu Yazar

Mehmet Musa ASLAN

Muş Devlet Hastanesi Kadın Doğum

Kliniği, MUŞ

Tel: 05326364706

Email : jinopdrmma@gmail.com

\section{Comparison Of Endometrial Pathology Results in Tamoxifen Or Tamoxıfen+Leuprolid Acetate}

\section{Therapy in Breast Cancer Women}

Vedat UĞUREL ${ }^{1}$, Mehmet Musa ASLAN ${ }^{2}$

\begin{abstract}
The effects of addition of GnRH agonist on endometrial pathology and endometrial cancer rates in tamoxifen use in breast cancer patients. A retrospective study of 204 patients who were operated for breast cancer between 1998 and 2013 and who underwent endometrial sampling at the gynecology clinic of Trakya University Medical Faculty, were divided into two group as treatment with tamoxifen and tamoxifen+GnRH agonist(leuprolide acetate depot 11.25 $\mathrm{mg}$ ). There were no differences between the groups in terms of endometrial thickness in the ultrasound examination, endometrial pathology in the histopathological examination and incidence of endometrial cancer among the premenopausal women using tamoxifen $+\mathrm{GnRH}$ and the the postmenopause women using tamoxifen. We found that the addition of a GnRH analog to the treatment of tamoxifen in breast cancer patients did not increase the risk of premalignant lesion and endometrium ca in premenopausal women.
\end{abstract}

Keywords: Breast cancer, tamoxifen, GnRH analgesic, leuprolide acetate, endometrial pathology, endometrial cancer
Article Info

Received:14.09.2018

Accepted:13.11.2018

Online Published:30.06.2019

DOI: $10.26453 /$ otjhs.460155

Corresponding Author

Mehmet Musa ASLAN

Muş Devlet Hastanesi Kadın Doğum

Kliniği, MUŞ

Tel: 05326364706

Email : jinopdrmma@gmail.com

${ }^{1}$ Trakya Üniversitesi Tıp Fakültesi Kadın Hastalıkları ve Doğum Kliniği, Edirne, Türkiye.

${ }^{2}$ Muş Devlet Hastanesi Kadın Hastalıkları ve Doğum Kliniği, Muş, Türkiye.

\section{GíRiş}

Tamoksifen östrojen reseptör pozitif meme

kanserli kadınlarda yardımcı tedavi olarak

kullanılan bir ilaçtır. Tamoksifen steroid olmayan selektif östrojen modülatörüdür. Memedeki östrojen reseptörleri üzerine antagonist etki gösterirken, endometrium üzerine 1lımlı agonist etki göstermektedir. Standart dozlarda tamoksifen 
endometrial proliferasyon, hiperplazi, polip formasyonu, invaziv karsinom ve uterin sarkom ile ilişkilidir. ${ }^{1}$ Tamoksifene bağlı endometrial kanser gelişme riski kullanım zamanına bağımlıdır. Üç yıl aralıksız kullanım sonrası istatiksel anlamlı düzeye ulaşır. ${ }^{2}$ Tamoksifen kullanan olgular endometrial patolojiler açısından yıllık jinekolojik muayene ve transvajinal ultrason ile takip edilir. Ultrasonda endometrial patolojiden kuşku duyulması durumunda veya vajinal kanama gibi semptomu olan kadınlarda endometrial örnekleme yapılabilir. Vajinal kanama gibi semptom varlığında endometrial biyopsi veya histerektomi materyalinde endometrial patoloji görülme riski artmaktadir. $^{3}$

Gonadotropin hormon agonistleri (GnRH-a) baz1 meme kanserli olgularda tamoksifene ek olarak kullanılmaktadır. GnRH-a ilk başta hipotalamik GnRH reseptörlerine bağlanarak alevlenme etkisi gösterirken, sonrasında duyarsızlaştırma etkisi gösteren sentetik peptidlerdir. Premenopozal östrojen reseptörü pozitif $(\mathrm{ER}+)$ meme kanserli kadınlarda hipotalamik-pitüiter-ovaryan aksta geçici down regülasyon ile postmenopozal gonadotropin hormon seviyelerinin oluşmasını sağlar. Meme kanserli olgularda GnRH-a verilmesi ile ilgili yayınlar, meme kanseri rekürrens ve sağkalım oranları ile meme kanseri cerrahisi geçirmiş kemoterapi alacak olanlarda ovaryan foliküler rezervi korumaya yönelik etkisini araştırmaya yöneliktir. ${ }^{4}$ GnRH-a'nın tamoksifen alan meme kanserli olgularda endometrium üzerine koruyucu etkisi olup olmadığ 1 bilinmemektedir. Endometrial patolojiler ile invitro hücre kültürlerinde endometrium kanserli hücrelerin proliferasyonunu baskıladığ1 görülmüştür., ${ }^{5,6}$ Ancak endometrial patolojiler üzerine invivo etkisi kanıtlanamamıştır. $\mathrm{Bu}$ çalışmanın amacı GnRH-a kullanımının meme kanserli olgularda tamoksifen ilişkili endometrial patolojileri önleyip önlemediğini araştırmaktır.

\section{MATERYAL VE METOT}

Bu çalışma retrospektif olarak yapılmıştır.1998 ile 2013 yılları arasında meme kanseri nedeniyle opere olan ve Trakya Üniversitesi Tıp Fakültesi Hastanesi jinekoloji polikliniğinde endometriyal örnekleme yapılan 204 olgunun dosyası incelenerek yapıldı. Trakya Üniversitesi Tıp Fakültesi girişimsel olmayan klinik araştırmalar etik kurulundan onay alınd1. Olgular sadece tamoksifen ve tamoksifene+ GnRH agonist (leuprolide acetate depot $11,25 \mathrm{mg}$ ) tedavisi alanlar olarak iki gruba ayrıldı. Vajinal kanaması olanlar, postmenopozal dönemde transvajinal ultrasonda endometrium kalınlığ $5 \mathrm{~mm}$ ve üzeri olanlar ile tedavi öncesi bulunmadığı halde tedavi sonrası uterin kavitede beliren hiperekojen lezyonu bulunan olgulara yapilan endometrial örneklemeler çalışmaya dahil edildi. Transvaginal ultrasonda endometrial kalınlık ölçümleri tek bir hekim tarafindan yapılıp ardından endometrial örneklemeler yine aynı hekim tarafından yapılan 
olgular çalışmaya dahil edildi. Meme kanseri remisyonda olmayan olgular ile asemptomatik, transvajinal ultrasonda endometrium kalınlığ $4 \mathrm{~mm}$ ve daha az olanlar, endometrial düzensizliği olmayanlar, ultrasonda endometrial patolojiyi düşündüren bulgusu olmayanlar endometrial örnekleme endikasyonu bulunmadığından çalışmaya dahil edilmedi.

Olguların demografik verileri, menopozal durumu, başvuru semptomları, ultrason bulguları, ilaç kullanım bilgileri kaydedildi. Gruplar arasında endometrial patoloji görülme oranları karşılaştırıldı. Ayrıca gruplar arasında endometrial patoloji görülme oranlarının premenopoz ve postmenopozal durum ile ilişkisi araştırıldı.

\section{İstatistik ve Analiz}

Sürekli değişkenler ortalama \pm standart sapma ya da medyan (minimum:maksimum) değerleriyle ifade edildi. Kategorik değişkenler ise n (\%) ile ifade edildi. Kategorik değişkenlerin gruplar arasında yapılan karşılaştırmalarında ki-kare testi kullanıldı. Sürekli değişkenlerin gruplar arasında yapılan karşılaştırmalarında Mann Whitney u testi kullanıld1. Kolmogorov Smirnov testi ile tedavi öncesi endometrial kalınlık değerlerinde tedaviyi takiben biyopsi öncesi değişim saptand1. Wilcoxon Signed Rank testi ile iki grup arasında endometriyal kalınlıkları arasında fark olup olmadığı araştırıldı. İstatistiksel analizler için SPSS (IBM Corp. Released 2012. IBM SPSS Statistics for Windows, Version 21.0. Armonk,
NY: IBM Corp.) programı kullanıldı. $\mathrm{p}<0,05$ değeri istatistiksel olarak anlamlı kabul edildi.

\section{BULGULAR}

Çalışmada sadece tamoksifen (1. grup) alan grupta 129 postmenopozal, tamoksifen+ leuprolid asetat alan (2. grup) grupta 75 premenopozal olmak üzere toplam 204 kadın bulunmaktadır (Tablo 1). İkinci grubun ortanca yaşı birinci gruba göre daha genç olarak bulundu $(\mathrm{p}=0,00)$. Tamoksifen kullanım süresi, tamoksifen başlanmasından endometrial biyopsi alınmasına kadar geçen süre, tamoksifen başlama öncesi endometrial kalınlık, endometrial biyopsi öncesi endometrial kalınlık, endometrial biyopsi öncesi endometrial kalınlık ile tamoksifen öncesi endometrial kalınlık farkı, biyopside endomerial patoloji bulunma oranı, endometrial kanser görülme oranları açısından gruplar arasında fark bulunmadi $(p>0,05)$.

Endometrial örnekleme sonucu benign olarak rapor edilenler ile malign olarak rapor edilenler karşılaştırıldı (Tablo 2). Sonuç malign olarak rapor edilenlerde tamoksifen kullanma süresi daha uzundu ( $\mathrm{p}=0,003)$. Malign olanlarda tedavi sonrası biyopsi alınmasına kadar geçen süre daha uzundu $(\mathrm{p}=0,008)$. Tamoksifen tedavisi öncesi endometrial kalınlık arasında fark yoktu $(\mathrm{p}>0,05)$. Malign olgularda endometrial biyopsi alınma sırasında endometrial kalınlık daha fazla ölçüldü $(p=0,00)$. Endometrial biyopsi öncesi endometrial kalınlık ile tamoksifen öncesi endometrial kalınlık 
fark1 benign olgularda daha fazla olarak hesapland $1(\mathrm{p}=0,034)$.

\section{TARTIŞMA VE SONUÇ}

Tamoksifen meme kanserli olgularda kullanılmakta olup endometrial kanser gelişme ihtimalini artırmaktadır. GnRH agonistlerinin tamoksifen kullanan olgularda endometrium üzerine koruyucu etkileri olup olmadığ belirsizdir. Meme kanserli olgularda GnRH-a kullanımı ile ilgili çalışmalar daha çok over rezervini ve fertiliteyi korumaya odaklanmıştır. Erken menopozun önlenmesi çalışmasında [POEMS] hormon reseptörü negatif premenopozal kadınlara kemoterapi ile birlikte GnRH-a verilmesinin daha az prematür over yetmezliği ile ilişkili olduğu bulunmuştur. ${ }^{5}$

$\mathrm{GnRH}$ analoğu verilmesinin endometrium üzerine etkilerini inceleyen in vitro çalışmalar mevcuttur. Luteinize hormone-releasing hormone (LHRH) eklenmesi endometrium kanser hücre kültüründe, hücre büyümesini inhibe ettiği gösterilmiştir. ${ }^{6}$ Benzer şekilde başka bir in vitro çalışmada $\mathrm{GnRH}$ agonisti endometrial hücrelerinin büyümesini inhibe etmiştir. Ancak endometrial patolojiler üzerine invivo etkisi kanıtlanamamıştır. $\mathrm{Bu}$ çalışmada tamoksifen verilen grup ile tamoksifene ilave olarak GnRH analoğu verilen grup arasında endometrial kanser başta olmak üzere endometrial patoloji görülme oranları benzer olarak bulundu. ${ }^{6}$ Yapılan bir çalışmada meme kanserinde tamoksifen kullanımının 49 yaş altındaki olgularda endometrial kanser görülme oranlarını anlamlı olarak artırmazken, 50 yaş ve üzeri kadınlarda risk oranı 4,01 (95\% güven aralığı, 1,70-10,90) olacak şekilde artırdığı bulunmuştur. ${ }^{8}$ Başka bir çalışmada ise premenopozal meme kanserli olgularda tamoksifen alanlarla almayanlar arasında ultrason incelemesinde endometrial kalınlık, uterin hacim veya histopatolojik bulgular açısından fark bulunmamıştır. Ancak postmenopozal kadınlarda tamoksifen kullanımı uterusta daha fazla anormallik ile ilişkili bulunmuştur. ${ }^{9} \quad$ Postmenapozal kadınlarda tamoksifen endometriumda bazı değişikliklere sebep olmaktadır.Yapılan metaanalizde bu değişikliklerden dolayı endometrial kalınlık herzaman tek başına endometrial örnekleme için yeterli bir bulgu olmadığı belirtilmiştir. Postmenopozal kadınlarda anormal uterin kanamanın varlığı endometrial örnekleme için ultrason görüntüsüne göre daha anlamlı bulunmuştur. ${ }^{10}$ Bizim çalışmamızda hem anormal uterin kanaması olanlara hem de endometrium kalınlığı $5 \mathrm{~mm}$ ve üzeri olanlara örnekleme yapılmıştır. Eğer sadece anormal uterin kanaması olanlara endometrial örnekleme yapılmış olsaydı sonuç farklı olabilirdi.Bu çalışmamızda GnRH-a, tamoksifen kullanımında endometrial patoloji görülme ihtimali daha yüksek olan postmenopozal kadınlar yerine daha önceki yayınlarda belirtilen kaygılarla premenopozal kadınlara verilmiştir. Dolayısı ile riskin arttığ postmenopozal kadınlarda GnRH-a kullananlar ile 
kullanmayanlar arasında endometrial kalınlık ve histopatolojik bulgular açısından karşılaştırılamadı. $\mathrm{Bu}$ durum çalışmamızın limitasyonu olarak kabul edilebilir. Prospektif randomize geniş serili çalışmalarla GnRH-a kullanımının meme kanserli tamoksifen kullanan postmenopozal kadınlardaki endometrial etkilerinin araştırılmasına ihtiyaç olduğunu düşünmekteyiz.

Sonuç olarak, meme kanseri nedeniyle tamoksifen ile birlikte GnRH analoğu kullanan premenopozal kadınlar ile sadece tamoksifen kullanan postmenopoz kadinlar arasinda ultrason incelemesinde endometrial kalınlık, histopatolojik incelemede endometrial patoloji bulunma ve endometrial kanser görülme oranları açısından gruplar arasında fark bulunmadi.

Ancak bu konuda geniş randomize kontrollü çalışmalara ihtiyaç vardır.

\section{KAYNAKLAR}

1. Committee Opinion No.601: Tamoxifen and uterine cancer. Obstet Gynecol. 2014;123(6):1394-1397.

2. Chen JY, Kuo SJ, Liaw YP, et al. Endometrial cancer incidence in breast cancer patients correlating with age and duration of tamoxifen use: a population based study. Journal of Cancer. 2014;5:151-155.

3. Deligdisch L, Kalir T, Cohen CJ, de Latour M, Le Bouedec G, Penault-Llorca F. Endometrial histopathology in 700 patients treated with tamoxifen for breast cancer. Gynecologic oncology. 2000;78:181-186.

4. Kim J, Kim M, Lee JH, et al. Ovarian function preservation with GnRH agonist in young breast cancer patients: does it impede the effect of adjuvant chemotherapy? Breast. 2014;23(5):670-675.

5. Moore HC, Unger JM, Phillips KA, Boyle FM, Hitre E, Porter DJ, et al. Phase III trial (Prevention of Early Menopause Study [POEMS]-SWOG S0230) of LHRH analog during chemotherapy (CT) to reduce ovarian failure in early-stage, hormone receptornegative breast cancer: an international Intergroup trial of SWOG, IBCSG, ECOG, and CALGB (Alliance). J Clin Oncol. 2014;32:15s (Suppl.; abstr LBA505).

6. Noci I, Coronnello M, Borri P, et al. Inhibitory effect of luteinising hormone-releasing hormone analogues on human endometrial cancer in vitro. Cancer Lett. 2000,13;150(1):71-78.

7. Sica G, Schinzari G, Angelucci C, Lama G, Iacopino F. Direct effects of GnRH agonists in human hormone-sensitive endometrial cells. Mol Cell Endocrinol. 2001,15;176(1-2):121128.

8. Fisher B, Costantino JP, Wickerham DL, et al. Tamoxifen for prevention of breast cancer: report of the National Surgical Adjuvant Breast 
and Bowel Project P-1 Study. J Natl Cancer Inst. 1998;90:1371-1388.

9. Cheng WF, Lin HH, Torng PL, Huang SC. Comparison of endometrial changes among symptomatic tamoxifen- treated and nontreated premenopausal and postmenopausal breast cancer patients. Gynecol Oncol. 1997;66:233237.
10. Committee on Practice Bulletins Gynecology. Practice bulletin no. 128: diagnosis of abnormal uterine bleeding in reproductiveaged women. Obstet Gynecol 2012; 120:197. Reaffirmed 2016. 
Tablo 1. Grupların yaş, tedavi ve endometrial patolojiler açısından karşılaştırılması

\begin{tabular}{lccc}
\hline $\mathbf{N = 2 0 4}$ & $\begin{array}{c}\text { Grup 1 (n=129) } \\
\text { postmenopoz }\end{array}$ & $\begin{array}{c}\text { Grup 2 (n=75) } \\
\text { premenopoz }\end{array}$ & p \\
\hline Yaş & $50(40-79)$ & $40(25-48)$ & $\mathbf{0 . 0 0}$ \\
Tmx kullanma süresi (ay) & $36(6-120)$ & $36(6-96)$ & 0.47 \\
$\begin{array}{l}\text { Illk endometrial biyopsi } \\
\text { alınma süresi (ay) }\end{array}$ & $12(1-60)$ & $12(3-60)$ & 0.31 \\
$\begin{array}{l}\text { Tmx tedavisi öncesi EK } \\
\text { (mm) }\end{array}$ & $4(1.7-6.9)$ & $4(1.9-7.5)$ & 0.42 \\
$\begin{array}{l}\text { Endometrial biyopsi öncesi } \\
\text { EK (mm) }\end{array}$ & $7.6(5-19)$ & $7.4(5-19)$ & 0.81 \\
$\delta$ EK* (mm) & $4.1(0.5-16)$ & $3.9(0.1-14.8)$ & 0.66 \\
Endometrial patoloji** (n) & $42(32,6 \%)$ & $26(34,7 \%)$ & 0.75 \\
Endometrial kanser (n) & $8(6.2 \%)$ & $6(8 \%)$ & 0.62 \\
\hline
\end{tabular}

EK: Endometrial kalınlık

Tmx: Tamoksifen

* $\delta E K$ (Endometrial biyopsi öncesi endometrial kalınlı (mm)-Tmx tedavisi öncesi endometrial kalınlık (mm))

**Endometrial patoloji endometrial polip, endometrial hiperplazi, endometrial kanseri kapsamaktadır 
Tablo 2. Benign ve malign endometrial biyopsi sonuçlarının klinik bilgilerinin karşılaştırılması

\begin{tabular}{lccc}
\hline & $\begin{array}{c}\text { Benign patoloji* } \\
(\mathbf{n = 5 4})\end{array}$ & $\begin{array}{c}\text { Malign patoloji } \\
(\mathbf{n = 1 4})\end{array}$ & $\mathbf{p}$ \\
\hline $\begin{array}{l}\text { Tmx kullanma süresi (ay) } \\
\text { Ilk endometrial biyopsi } \\
\text { alınma süresi (ay) }\end{array}$ & $12(1-60)$ & $60(12-72)$ & $\mathbf{0 . 0 0 3}$ \\
$\begin{array}{l}\text { Tmx tedavisi öncesi EK } \\
\text { (mm) }\end{array}$ & $4(1.7-7.5)$ & $24(12-48)$ & $\mathbf{0 , 0 0 8}$ \\
$\begin{array}{l}\text { Endometrial biyopsi } \\
\text { öncesi EK (mm) }\end{array}$ & $4.2(2-5.6)$ & 0.74 \\
$\delta$ EK $* *$ (mm) & $7.4(5-19)$ & $11.75(7-17)$ & $\mathbf{0 . 0 0}$ \\
\hline
\end{tabular}

*Benign patoloji endometrial polip, endometrial hiperplazi ve specific olmayan endometrial değişiklikleri kapsamaktadır. ** $\delta E K$ (Endometrial biyopsi öncesi endometrial kalınlı (mm)-Tmx tedavisi öncesi endometrial kalınlı (mm)) 